\title{
Effects of Exercise Training on Circulating Retinol-Binding Protein 4 and Cardiovascular Disease Risk Factors in Obese Men
}

\author{
Shigeharu Numao ${ }^{a, b}$ Hiroyuki Sasaic, d Yasuhiro Nomata ${ }^{e}$ \\ Tomoaki Matsuo $^{f}$ Miki Eto $^{\text {e }}$ Takehiko Tsujimoto ${ }^{g}$ Kiyoji Tanakah \\ a Department of Health and Sports Sciences, Kyoto Pharmaceutical University, Kyoto, \\ bWaseda Institute for Sport Sciences, Saitama, ' Diabetes, Endocrinology and Obesity \\ Branch, National Institute of Diabetes and Digestive and Kidney Diseases, National \\ Institutes of Health, Bethesda, MD, USA, d Japan Society for the Promotion of Science, \\ Tokyo, ${ }^{e}$ Division of Sports Medicine, Graduate School of Comprehensive Human Sciences, \\ University of Tsukuba, ${ }^{\mathrm{f} J a p a n}$ Aerospace Exploration Agency, ${ }^{9}$ Doctoral Program in Sports \\ Medicine, Graduate School of Comprehensive Human Sciences, University of Tsukuba, \\ hFaculty of Health and Sport Sciences, University of Tsukuba, Ibaraki, Japan
}

Key Words

Obesity $\cdot$ Triglycerides $\cdot$ High-density lipoprotein cholesterol

\begin{abstract}
Introduction: The purpose of this study was to investigate the effects of 12 -week exercise training on circulating retinol-binding protein 4 (RBP4) concentration and cardiovascular disease (CVD) risk factors in obese men. Methods: 29 obese men (age $48 \pm 2$ years; BMI $29.6 \pm$ $0.7 \mathrm{~kg} / \mathrm{m}^{2}$ ) participated in a 12-week exercise program (50-70\% maximal heart rates; 3 times/ week) without calorie restriction. Anthropometric parameters, CVD risk factors (total cholesterol, high-density lipoprotein cholesterol (HDLC), low-density lipoprotein cholesterol, triglycerides (TG), and quantitative insulin sensitivity check index), and circulating RBP4 and adipokine (adiponectin, leptin, and interleukin-6 (IL-6)) concentrations were measured. $\boldsymbol{R e}$ sults: Exercise training significantly improved in absolute peak oxygen consumption ( $p<$ $0.05)$, and CVD risk factors $(p<0.05)$, with the exception of HDLC. There was a significant decrease in circulating RBP4, leptin, and IL- 6 concentrations $(p<0.05)$. Stepwise regression analysis revealed that changes in RBP4 concentration were independently related to the changes in TG concentration $(\beta=0.46, p<0.05)$. Conclusion: These results demonstrate that exercise training without calorie restriction improves several CVD risk factors and circulating RBP4 and adipokine concentrations. Moreover, the change in circulating RBP4 may be more associated with the improvements in TG concentration in obese men. Copyright $\odot 2012 \mathrm{~S}$. Karger GmbH, Freiburg
\end{abstract}


Numao et al.: Effects of Exercise Training on Circulating Retinol-Binding Protein 4 and Cardiovascular Disease Risk Factors in Obese Men

\section{Introduction}

Obesity is a worldwide epidemic [1, 2], and is associated with debilitating health problems. Obesity has increased the incidence of cardiovascular disease (CVD) risk factors including in type 2 diabetes, dyslipidemia, and hypertension [3]. It is believed that the metabolic abnormalities induced by obesity are partly linked to change in the production and secretion of adipokines; these are proteins secreted from adipose tissue that influence metabolic actions. Many studies have demonstrated an association between circulating adipokine levels, including adiponectin, leptin and interleukin-6 (IL-6), and CVD risk factors [4].

Retinol-binding protein 4 (RBP4) is the only specific transport protein for retinol (vitamin A) in the circulation, and its single known function is to deliver retinol to tissues via the blood [5]. Recently, Yang et al. [6] showed that insulin resistance in the liver and skeletal muscle of mice was associated with elevated circulating levels of adipose tissuederived RBP4. In humans, obese subjects with impaired glucose tolerance and type 2 diabetes have a higher level of circulating RBP4 than normal glucose-tolerant people [6-8]. Moreover, circulating RBP4 concentrations are associated with insulin resistance and other CVD risk factors [7-14].

Chronic exercise training is recommended for treatment of obesity and has beneficial effects on obesity-associated metabolic abnormalities. The effects of exercise training on metabolic abnormalities may be partly mediated by changes in circulating RBP4 concentration. Graham et al. [8] reported that 1-month exercise training reduced circulating RBP4 concentration only in subjects with improved insulin resistance. In addition, they found that the change in circulating RBP4 concentration negatively correlated with changes in glucose disposal rate after exercise training in subjects with impaired glucose tolerance or type 2 diabetes. However, studies investigating the effect of exercise training on circulating RBP4 concentration in obese subjects are limited. In addition, the effects of exercise-induced changes on the levels of circulating RBP4 and CVD risk factors are unknown. To prevent CVD in obese populations, it is important to assess the effect of exercise training on circulating RBP4 concentration and to understand the association between RBP4 and CVD risk factors.

The purpose of this study was to determine the effect of exercise training on circulating RBP4 concentration and CVD risk factors and to evaluate the association between the change in circulating RBP4 concentration and CVD risk factors induced by exercise training in obese men.

\section{Participants and Methods}

\section{Participants}

Participants were recruited through advertisements in local newspapers. Inclusion criteria were: i) no a history of acute or chronic disease (CVD, cerebrovascular disease, liver disease, renal disease, or cancer) ii) fasting glucose concentrations $<7.0 \mathrm{mmol} / \mathrm{l}$ (126 mg/dl) [15], and iii) BMI $\geq 25 \mathrm{~kg} / \mathrm{m}^{2}$ [16]. In total, 38 obese men who met the criteria enrolled as the study participants and engaged in a 12 -week exercise program; 9 with incomplete data were excluded from the study. Hence, 29 men were included in the analyses (table 1). All participants were sedentary (spontaneous physical activity $<3$ times/week), weight stable $(<3 \mathrm{~kg}$ change in body mass) for at least 2 months, and were not taking medicines that affected carbohydrate and fat metabolism. This investigation was carried out in accordance with the principles of the Declaration of Helsinki and was approved by the institutional review board at the University of Tsukuba. The purpose, design, and risks of this study were explained to all participants, and written informed consent was obtained. 
Numao et al.: Effects of Exercise Training on Circulating Retinol-Binding Protein 4 and Cardiovascular Disease Risk Factors in Obese Men

Table 1. Changes of participants characteristics at baseline and after 12-week exercise traininga

\begin{tabular}{|c|c|c|}
\hline & \multicolumn{2}{|c|}{ Exercise $(n=29)$} \\
\hline & pre & post \\
\hline Age, years & $48 \pm 2$ & \\
\hline Height, $\mathrm{cm}$ & $170 \pm 1$ & \\
\hline Body mass, $\mathrm{kg}$ & $86 \pm 2$ & $82 \pm 2^{*}$ \\
\hline BMI, $\mathrm{kg} / \mathrm{m}^{2}$ & $29.6 \pm 0.7$ & $28.3 \pm 0.6^{*}$ \\
\hline Waist circumference, $\mathrm{cm}$ & $100.8 \pm 1.3$ & $96.0 \pm 1.4^{*}$ \\
\hline$\%$ Body fat, $\%$ & $30.8 \pm 1.0$ & $28.0 \pm 1.1^{*}$ \\
\hline Body fat mass, $\mathrm{kg}$ & $26.4 \pm 1.3$ & $23.2 \pm 1.3^{*}$ \\
\hline Lean tissue mass, kg & $57.0 \pm 1.7$ & $57.0 \pm 1.6$ \\
\hline $\mathrm{Vo}_{2}$ peak, $\mathrm{ml} / \mathrm{min}$ & $2,575 \pm 97$ & $2,904 \pm 100^{*}$ \\
\hline $\mathrm{Vo}_{2}$ peak, $\mathrm{ml} / \mathrm{kg} / \mathrm{min}$ & $30.2 \pm 0.9$ & $35.5 \pm 0.8^{*}$ \\
\hline TFA, $\mathrm{cm}^{2}$ & $401 \pm 20$ & $336 \pm 17^{*}$ \\
\hline VFA, $\mathrm{cm}^{2}$ & $192 \pm 10$ & $161 \pm 9^{*}$ \\
\hline $\mathrm{SFA}, \mathrm{cm}^{2}$ & $209 \pm 14$ & $175 \pm 12^{*}$ \\
\hline
\end{tabular}

\section{Body Composition}

Height was measured to the nearest $0.1 \mathrm{~cm}$ using a wall-mounted stadiometer, and body mass was measured to the nearest $0.1 \mathrm{~kg}$ using a calibrated electronic digital scale (TBF-215; Tanita, Tokyo, Japan). BMI was calculated by dividing body mass $(\mathrm{kg})$ by the square of the height $\left(\mathrm{m}^{2}\right)$. Waist circumference was measured at the level of the umbilicus to the nearest $0.1 \mathrm{~cm}$ using non-elastic tape. Whole-body fat mass and lean tissue mass were measured by dual-energy X-ray absorptiometry (Lunar DPX-NT densitometer, Lunar, Madison, WI, USA). Pixels of soft tissue were used to calculate the ratio of mass attenuation coefficients ( $\mathrm{R}$ value) at 40-59 keV (low energy) and 80-100 keV (high energy). The data were analyzed using the software supplied by the manufacturer. The within-participants coefficients of variation of this instrument in our laboratory have been previously reported as $2.5 \%$ for whole-body fat mass and $0.5 \%$ for lean tissue mass [17]. Abdominal fat (i.e., total abdominal fat area (TFA), visceral fat area (VFA) and abdominal subcutaneous fat area (SFA)) was measured by a computed tomography scan (Somatom AR.C; Siemens, Munich, Germany) while participants were in the supine position. A single $5 \mathrm{~mm}$ scan was obtained with a scanning time of $5 \mathrm{~s}$ centered at the level of the umbilicus (4th and $5 \mathrm{~h}$ lumbar vertebrae). TFA, VFA, and SFA were calculated using the Fat Scan software program (N2system, Osaka, Japan).

\section{Aerobic Capacity Test (Peak Oxygen Consumption)}

Peak oxygen consumption ( $\mathrm{VO}_{2}$ peak) was determined by an incremental graded exercise test using cycle ergometer (828E; Monark, Stockholm, Sweden). During the test, expired air was analyzed using an indirect calorimeter (Oxycon Alpha, Mijnhard ${ }^{\mathrm{TM}}$, Breda, the Netherlands). The highest oxygen uptake achieved over $30 \mathrm{~s}$ was identified as the $\mathrm{VO}_{2}$ peak. The $\mathrm{VO}_{2}$ peak was defined by the criteria described by Tanaka et al. [18]. Briefly, the $\mathrm{VO}_{2}$ peak occurred when i) the $\mathrm{VO}_{2}$ reached a plateau $(<150 \mathrm{ml} / \mathrm{min})$ despite increasing exercise intensity, ii) the highest respiratory exchange ratio during the final stage of the incremental exercise was $>1.10$, and iii) the highest heart rate (HR) measured during the last minute of exercise was $>90 \%$ of the predicted maximal HR (220 - age in years).

\section{Blood Pressure}

Systolic and diastolic blood pressures were measured to the nearest $1 \mathrm{~mm} \mathrm{Hg}$ using a mercury manometer after resting for $30 \mathrm{~min}$. The lower value of two readings was taken as the outcome measures.

\section{Exercise Intervention}

All exercise sessions were supervised by experienced physical trainers and were conducted at the research center of the University of Tsukuba. Participants performed 90 min of exercise training 3 days/ week for 12 weeks. The exercise training consisted of 45-60 min aerobic exercise (brisk walking, mild jogging, and/or aerobic dancing) and 15-25 min recreational and cool-down activities. The aerobic 
exercise intensity was based on the percentage of age-predict maximal HR attained by each participant. The participants were monitored during each exercise session using HR monitor (RS 400, Polar Electro Accurex Plus); they targeted at 50-70\% of their maximum HR during aerobic exercise session.

\section{Physical Activity and Diet}

Daily physical activity was assessed using a uniaxial accelerometry sensor (Lifecorder; Suzuken, Tokyo, Japan). The sensor was attached to the participant at waist level for 2 weeks before the start of training for baseline testing. It remained attached throughout the 12-week exercise training period, except when the participant performed activities involving water such as taking a bath and swimming.

During the 12-week exercise training, participants were instructed not to change their dietary intake to ensure that analyses were only evaluating the effects of exercise on adipokine concentrations and CVD risk factors. To evaluate the adherence to dietary intake, all participants were recorded and interviewed the contents of their diet for 3 days before and during (weeks 9-10) the exercise training. A skilled dietitian used the dietary records to calculate protein, fat, carbohydrate, and total energy intake for each participant using a commercially available computer program.

\section{Biochemical Analysis}

Venous blood samples were drawn from each participant after an overnight fasting ( $>8 \mathrm{~h})$. The samples were stored at $-80^{\circ} \mathrm{C}$ until biochemical assay. Serum total cholesterol (TC) and triglycerides (TG) concentrations were determined enzymatically, serum high-density lipoprotein cholesterol (HDLC) concentration was measured by the heparin-manganese precipitation method, and serum low-density lipoprotein cholesterol (LDLC) concentration was estimated according to the equation of Friedewald et al. [19]. Fasting blood glucose concentration was assayed by the glucose oxidase method. Serum insulin concentration was measured by radioimmunoassay. Hemoglobin A1c (HbA1c) was measured by particleenhanced immunoturbidimetric assay. The inter- and intra-assay coefficients of variation of the above parameters were $<5 \%$. The quantitative insulin sensitivity check index (QUICKI) is a simple index based on the glucose and insulin levels in a fasting blood sample and was calculated as follows: 1 / (log insulin $(\mu \mathrm{U} / \mathrm{ml})+\log$ glucose $(\mathrm{mg} / \mathrm{dl}))[20]$.

Enzyme-linked immunosorbent assay kits were used to measure serum adiponectin (Otsuka Pharmaceutical co., Tokyo, Japan; intra- and inter-assay coefficients $<10 \%$ and $<10 \%$, respectively), RBP4 (R\&D Systems, Minneapolis, MN, USA; intra- and inter-assay coefficients $<8.1 \%$ and $<8.6 \%$, respectively), leptin (R\&D Systems; intra- and inter-assay coefficients $<2.8 \%$ and $<3.2 \%$, respectively), and IL-6 (R\&D Systems; intra- and inter-assay coefficients $<4.2 \%$ and $<6.4 \%$, respectively) concentrations. Serum highsensitive C-reaction protein (hsCRP) concentration was determined by an immunonephelometric assay (intra- and inter-assay coefficients $<5 \%$ and $<5 \%$, respectively).

\section{Statistical Analysis}

Data are presented as means \pm SE. Paired t-tests were used to assess differences between variables before and after the exercise training. Pearson's correlation coefficient analysis was used to evaluate the associations between adipokine concentrations and CVD risk factors. A stepwise multiple regression analysis was performed to determine if the changes in adipokine levels were independently associated with changes in the CVD risk factors. The Shapiro-Wilk test was used to determine whether the variables had a normal distribution and if they were dependent or independent variables. Statistical significance was set at $<0.05$.

\section{Results}

Attendance and Exercise Intensity during Exercise Program

Attendance at the exercise program was $84.5 \pm 3.6 \%$, and exercise intensity during the sessions was $74.7 \pm 1.5 \%$ of the age-predicted maximal HR.

\section{Physical Activity and Diet}

The energy expenditure on physical activity assessed by a uniaxial accelerometry sensor significantly increased from $287 \pm 20$ to $477 \pm 26 \mathrm{kcal} /$ day $(\mathrm{p}<0.05)$ during the 
Table 2. Changes of cardiovascular diseases risk factors at baseline and after 12-week exercise training ${ }^{\mathrm{a}}$
Numao et al.: Effects of Exercise Training on Circulating Retinol-Binding Protein 4 and Cardiovascular Disease Risk Factors in Obese Men

\begin{tabular}{lll}
\hline & \multicolumn{2}{c}{ Exercise $(\mathrm{n}=29)$} \\
\cline { 2 - 3 } & pre & post \\
\hline SBP, mm Hg & $138 \pm 3$ & $132 \pm 3^{*}$ \\
DBP, mm Hg & $92 \pm 3$ & $89 \pm 3^{*}$ \\
TC, mmol/l & $5.9 \pm 0.2$ & $5.5 \pm 0.2^{*}$ \\
HDLC, mmol/l & $1.4 \pm 0.1$ & $1.5 \pm 0.1$ \\
LDLC, mmol/l & $3.6 \pm 0.2$ & $3.3 \pm 0.2^{*}$ \\
TG, mmol/l & $2.0 \pm 0.2$ & $1.4 \pm 0.1^{*}$ \\
Glucose, mmol/l & $5.3 \pm 0.1$ & $5.3 \pm 0.1$ \\
Insulin, pmol/l & $54.6 \pm 6.2$ & $42.3 \pm 7.1$ \\
HbA1c, \% & $5.4 \pm 0.1$ & $5.2 \pm 0.1^{*}$ \\
QUICKI & $0.35 \pm 0.01$ & $0.38 \pm 0.01^{*}$ \\
\hline \multicolumn{2}{l}{ SBP = Systolic blood pressure; DBP $=$ diastolic blood pressure. } \\
aValues are shown as mean \pm SE. \\
$\quad$ *Significantly different from pre value (p < 0.05). \\
\hline
\end{tabular}

12-week exercise training. The total energy (from 2,190 \pm 82 to $2,055 \pm 81 \mathrm{kcal} /$ day), protein (from $82 \pm 4$ to $83 \pm 4 \mathrm{~g}$ /day), fat (from $60 \pm 3$ to $57 \pm 3 \mathrm{~g} /$ day), and carbohydrate (from $289 \pm 16$ to $263 \pm 12 \mathrm{~g}$ /day) intake estimated from the dietary records did not significantly change ( $p>0.05)$

\section{Change in Body Composition and Aerobic Capacity}

Body mass, BMI, and whole-body fat mass significantly decreased (by $-4.3 \pm 0.5 \%$, $-0.3 \pm 0.5 \%$ and $-2.6 \pm 1.6 \%$, respectively; $\mathrm{p}<0.05$ ); lean tissue mass was maintained ( $p>0.05)$, and VFA and SFA also were decreased $(-17 \pm 3 \%$ and $-16 \pm 2 \%$, respectively) during 12-week exercise training. The absolute $\mathrm{VO}_{2}$ peak $(\mathrm{ml} / \mathrm{min})$ and the relative $\mathrm{VO}_{2}$ peak $(\mathrm{ml} / \mathrm{kg} / \mathrm{min})$ were increased $(14 \pm 2 \%$ and $19 \pm 2 \%$, respectively; $\mathrm{p}<0.05)$ in response to the exercise training (table 1 ).

\section{Change in Adipokine Concentrations and CVD Risk Factors}

Systolic blood pressure $(-4 \pm 1 \%)$, diastolic blood pressure $(-3 \pm 2 \%)$, serum TC $(-8 \pm 2 \%)$, LDLC $(-8 \pm 2 \%)$, and TG $(-21 \pm 7 \%)$ concentrations, $\mathrm{HbA}_{1} \mathrm{c}(-2.4 \pm 0.9 \%)$ as well as QUICKI $(8 \pm 3 \%)$ were improved after the exercise training $(\mathrm{p}<0.05)$ (table 2$)$.

Circulating RBP4 concentration significantly decreased (-8 $\pm 4 \%$; $<0.05)$, adiponectin concentration remained unchanged $(p>0.05)$, and there were significant decreases $(p<0.05)$ in serum leptin and IL-6 concentrations following exercise training. However, hsCRP concentration did not change ( $p>0.05)$ (table 3 ).

\section{Associations between Body Composition and CVD Risk Factors as well as Adipokine Concentrations}

Following the exercise training, the changes in BMI were positively correlated with the changes in TC concentration and HbA1c $(\mathrm{p}<0.05$; table 4). The changes in SFA were also positively correlated with the changes in TC concentration $(\mathrm{p}<0.05)$.

The changes in BMI, TFA, VFA, and SFA were positively correlated with the change in leptin concentration $(\mathrm{p}<0.05)$. There were no significant correlations between body composition variables and adipokine concentrations (RBP4, adiponectin, IL-6, and hsCRP) (table 4). 
Table 3. Changes of RBP4, adiponectin, leptin, hsCRP, and IL- 6 at baseline and after 12-week exercise training ${ }^{\mathrm{a}}$
Table 4. Correlation coefficients between changes of body composition, and changes of CVD risk factors and adipokines during 12-week exercise training
Numao et al.: Effects of Exercise Training on Circulating Retinol-Binding Protein 4 and Cardiovascular Disease Risk Factors in Obese Men

\begin{tabular}{lll}
\hline & \multicolumn{2}{l}{ Exercise $(\mathrm{n}=29)$} \\
\cline { 2 - 3 } & pre & post \\
\hline $\mathrm{RBP} 4, \mu \mathrm{g} / \mathrm{ml}$ & $55.4 \pm 3.4$ & $49.9 \pm 2.8^{*}$ \\
Adiponectin, $\mu \mathrm{g} / \mathrm{ml}$ & $4.5 \pm 0.4$ & $4.5 \pm 0.4$ \\
Leptin, ng/ml & $8.5 \pm 0.9$ & $4.7 \pm 0.7^{*}$ \\
IL-6, pg/ml & $2.09 \pm 0.40$ & $1.27 \pm 0.15^{*}$ \\
hsCRP, $\mu \mathrm{g} / \mathrm{l}$ & $1.26 \pm 0.29$ & $0.99 \pm 0.14$ \\
\hline
\end{tabular}

aalues are shown as mean $\pm \mathrm{SE}$.

*Significantly different from pre value $(\mathrm{p}<0.05)$.

\begin{tabular}{llllll}
\hline & $\Delta$ BMI & $\Delta$ Fat mass & $\Delta$ TFA & $\Delta$ VFA & $\Delta$ SFA \\
\hline CVD risk factors & & & & & \\
$\Delta$ SBP & -0.07 & -0.06 & 0.17 & 0.18 & 0.11 \\
$\Delta$ DBP & 0.18 & 0.17 & 0.23 & 0.15 & 0.31 \\
$\Delta$ TC & $0.49^{*}$ & 0.35 & 0.34 & 0.17 & $0.45^{*}$ \\
$\Delta$ HDLC & -0.13 & -0.11 & -0.03 & -0.06 & 0.02 \\
$\Delta$ LDLC & 0.30 & 0.26 & 0.26 & 0.23 & 0.23 \\
$\Delta$ TG & 0.37 & 0.24 & 0.20 & 0.03 & 0.35 \\
$\Delta$ Glucose & 0.08 & 0.12 & 0.04 & -0.01 & 0.09 \\
$\Delta$ Insulin & 0.14 & 0.02 & -0.11 & -0.15 & -0.04 \\
$\Delta$ HbA1c & $0.51^{*}$ & 0.30 & -0.14 & 0.00 & 0.26 \\
$\Delta$ QUICKI & -0.26 & -0.26 & -0.09 & -0.03 & -0.13 \\
\hline Adipokines & & & & & \\
$\Delta$ RBP4 & 0.26 & 0.31 & 0.00 & -0.13 & 0.15 \\
$\Delta$ Adiponectin & -0.14 & -0.30 & -0.08 & -0.18 & 0.04 \\
$\Delta$ Leptin & $0.52^{*}$ & 0.33 & $0.47^{*}$ & $0.38^{*}$ & $0.47^{*}$ \\
$\Delta$ IL-6 & 0.20 & 0.16 & 0.16 & 0.19 & 0.10 \\
$\Delta$ hsCRP & 0.00 & 0.02 & -0.06 & 0.03 & -0.13 \\
\hline
\end{tabular}

SBP = Systolic blood pressure; DBP = diastolic blood pressure. ${ }^{*} \mathrm{p}<0.05$.

Associations between Adipokine Concentration and CVD Risk Factors

At baseline, the circulating leptin concentrations were positively correlated with LDLC $(\mathrm{r}=0.40 ; \mathrm{p}<0.05)$ and insulin $(\mathrm{r}=0.39 ; \mathrm{p}<0.05)$ concentrations and negatively correlated with QUICKI ( $r=-0.40 ; \mathrm{p}<0.05$ ). No correlations between CVD risk factors and other adipokine concentrations (RBP4, adiponectin, IL-6, and hsCRP) were found.

Following the exercise training, the changes in circulating TG concentration were positively correlated with the changes in circulating RBP4 concentration $(r=0.46 ; p<0.05$; fig. 1). In addition, the changes in circulating HDLC concentration were positively correlated with the changes in adiponectin concentration $(r=0.43 ; p<0.05)$. The changes in fasting glucose concentration wereas positively correlated with the changes in circulating leptin concentration $(r=0.37 ; p=0.05)$. Stepwise multiple regression analysis was performed to identify the independent variable that predicted the changes in HDLC, TG, and fasting glucose concentration. Age, the change of $\mathrm{BMI}, \mathrm{VO}_{2}$ peak, abdominal fat area, adiponectin, 
Fig. 1.Relationship between the changes in circulating triglycerides and retinol-binding protein 4 concentrations during exercise training.
Numao et al.: Effects of Exercise Training on Circulating Retinol-Binding Protein 4 and Cardiovascular Disease Risk Factors in Obese Men

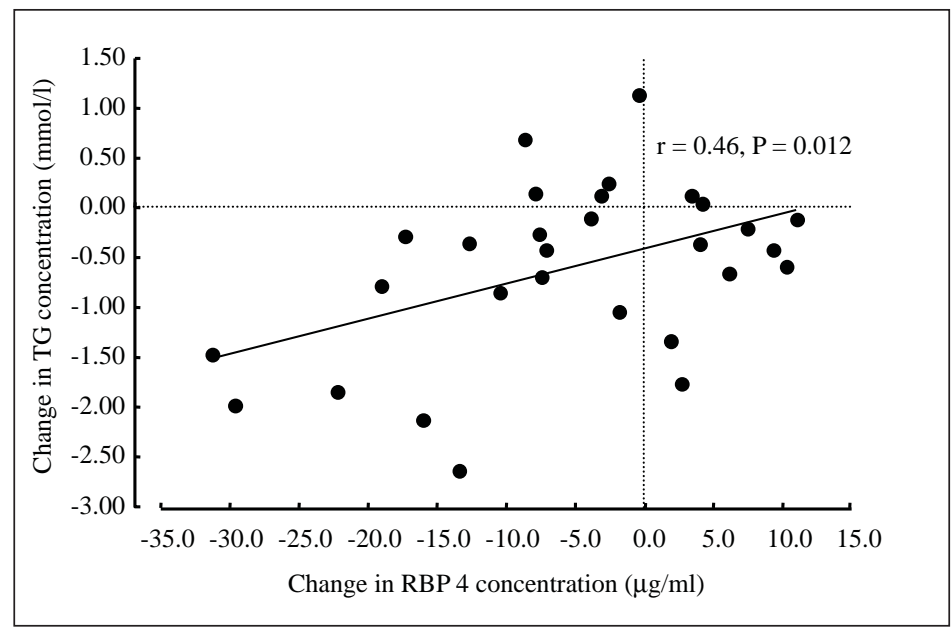

Table 5. Stepwise multiple linear regression analysis of obese men at baseline and after 12-week exercise training

\begin{tabular}{lllllll}
\hline Dependent variables & Independent variables & $\beta$ & $\beta_{\mathrm{SE}}$ & Standard $\beta$ & $\mathrm{p}$ value & $\mathrm{R}^{2}$ \\
\hline$\Delta$ TG & $\Delta$ RBP4 & 3.13 & 1.16 & 0.46 & 0.012 & 0.212 \\
$\Delta$ HDLC & $\Delta$ adiponectin & 4.67 & 1.78 & 0.45 & 0.014 & 0.203 \\
\hline
\end{tabular}

RBP4, leptin, IL-6, and hsCRP were used as independent variables. The changes in circulating RBP4 concentration and adiponectin concentration were independent predictors of the changes in TG $(\beta=0.46 ; p<0.05)$ and HDLC $(\beta=0.45 ; p<0.05)$ concentration, respectively (table 5).

\section{Discussion}

This study showed that 12 -week exercise training without calorie restriction improved CVD risk factors, and decreased circulating RBP4, leptin, and IL-6 concentrations in obese men. In particular, the exercise-induced change in RBP4 concentration was related to the improvement in TG concentration; this association was independent of age, the change in $\mathrm{BMI}, \mathrm{VO}_{2}$ peak, abdominal fat area, adiponectin, leptin, hsCRP, and IL-6.

Several studies demonstrated that circulating RBP4 concentrations decreased with body mass reduction after exercise training [8], calorie restriction [12, 21], and gastric bypass surgery $[11,14,22]$. Also, changes in circulating RBP4 concentrations were associated with the change in BMI $[11,22]$. Although BMI and RBP4 concentration decreased in our study, a relationship between the change of BMI and RBP4 concentration was not observed. In addition, the amount and contents of energy intake estimated from diet record remained unchanged. Moreover, absolute $\mathrm{VO}_{2}$ peak increased after the exercise training. These data suggest that exercise training contributes to the decrease in circulating RBP4 independent of body mass and energy intake.

The reduction in circulating RBP4 concentration induced by exercise training is in agreement with the results from studies in subjects with impaired glucose tolerance or type 
Numao et al.: Effects of Exercise Training on Circulating Retinol-Binding Protein 4 and Cardiovascular Disease Risk Factors in Obese Men

2 diabetes [8]. In contrast, RBP4 concentration remained unchanged after 3-month exercise training in obese women, even though these participants showed a greater weight loss than our participants [23]. These discrepancies may be partly explained by variation in baseline circulation RBP4 concentrations. In our study, the average baseline RBP4 concentration was $55.4 \pm 15.7 \mu \mathrm{g} / \mathrm{ml}$; Graham et al. [8] observed values of $59.9 \pm 32.8$ and $63.2 \pm 24.9 \mu \mathrm{g} / \mathrm{ml}$ in impaired glucose tolerance and type 2 diabetes subjects, respectively. In contrast, Choi et al. [23] found average an RBP4 value of $33.5 \pm 13.4 \mu \mathrm{g} / \mathrm{ml}$ at baseline in obese women. In our study, the baseline RBP4 concentration was negatively correlated with the decreased RBP4 concentration observed after exercise training (data not shown). Therefore, it is likely that the exercise-induced decrease in RBP4 concentration is dependent on the level of RBP4 concentration before exercise training.

Circulating RBP4 concentration has been associated with insulin resistance $[6,8,11]$; however, an association between changes in RBP4 concentration and insulin sensitivity was not observed. Several other studies also failed to find any association between the change of RBP4 concentration and insulin sensitivity after calorie restriction [21, 24] and gastric bypass surgery [14, 22]. Differences may be explained by variant insulin sensitivity indices and genetic variations. The QUICKI and homeostasis model for insulin resistance are commonly used [14, 21, 22, 24], and are simple indices derived from fasting glucose and insulin concentrations. These may be less accurate than the euglycemic-hyperinsulinemic clamp to detect relationships between RBP4 concentration and insulin sensitivity [24]. In addition, genetic variations in RBP4 [25-27] may suppress the improvement in insulin sensitivity. Therefore, the use of these simple indices and/or genetic variations may have masked the relationship between change of RBP4 concentration and insulin sensitivity in our study.

The association between circulating RBP4 and TG concentration has been reported in cross-sectional studies [8-10,13]. In addition, Broch et al. [14] found that a decrease in RBP4 level was related to a reduction in TG concentrations in obese women for 12 months after gastric bypass surgery. However, to our best knowledge, the present study is the first identifying an independent association between exercise-induced changes in circulating RBP4 and TG concentrations. The physiological mechanisms responsible for this association are unknown. Circulating RBP4 concentrations were increased by a selective decrease in glucose transporter 4 (GLUT4) in adipocytes [6]. Exercise training increased GLUT4 mRNA and protein expression in adipocytes $[28,29]$. The increase in GLUT4 protein and mRNA expression in adipocytes may have reduced circulating RBP4 concentration [6]. Moreover, RBP4 is the only specific transport protein for retinol (vitamin A) in the circulation [5], and retinoids increased hepatic production of very low density lipoprotein (VLDL) [30]. Broch et al. [14] proposed that the reduction in circulating RBP4 may indirectly decrease TG concentrations by decreasing the hepatic production of VLDL; fasting circulating TG is mainly contained in VLDL. Therefore, exercise training may increase GLUT4 in adipose tissues, which results in decreased circulating RBP4 concentrations, and partly contributes to improvement in circulating TG concentration.

Although circulating HDLC and adiponectin concentrations did not improve after exercise training, an independent association between the change in HDLC and adiponectin level was observed. This finding is supported by data from previous studies. HDLC was positively associated with adiponectin concentrations in a population without diabetes [31-34]. In addition, improvement in adiponectin was positively correlated with the increase in HDLC independently of change of BMI and insulin sensitivity after weight loss in an obese population [35]. It has been assumed that adiponectin regulates HDLC concentration through secretion or clearance of apoprotein A-1 in the liver [34, 36]. Therefore, our data suggest a possible direct link between the changes in HDLC and adiponectin concentration. 
Circulating leptin and IL- 6 concentrations improved after 12 weeks of exercise training. However, the improvements in leptin concentrations were correlated with changes of BMI and abdominal fat areas. Also, the improvement in leptin concentrations was no longer significant, after adjusted for BMI and abdominal fat areas (data not shown). It was shown that exercise training without weight and fat mass loss has no effect on leptin concentration [37-39]. Therefore, the reduction in leptin concentration may be mainly explained by the change of body composition. On the other hand, the change of IL- 6 was not associated with the changes of body composition variables. Our findings are consistent with other exercise training studies in obese populations [40], suggesting that exercise training has beneficial effects on IL- 6 concentrations independently of changes of body composition. However, no relationships between the improvement of CVD risk factors, and both circulating leptin and IL-6 concentration were found in our study. Although circulating adipokine concentrations have been associated with CVD risk factors [4], exercise-induced improvements in CVD risk factors do not appear to directly involve changes in circulating leptin and IL-6 concentrations.

There are several limitations in our study. First, this study had no control group (nonintervention group). In our study, physical activity energy expenditure increased and energy intake remained unchanged during a 12 -week exercise training program. These data demonstrate that exercise training itself improved CVD risk factors and adipokines. Nevertheless, further studies with a control group are required. Second, our findings on young men cannot be generalized because the response of RBP4 to exercise differs from that found in young and middle-aged women [41].

In conclusion, our study showed that a 12-week exercise training without diet restriction improved CVD risk factors and circulating RBP4 and adipokine levels in obese men. However, the change in circulating RBP4 level was independently associated with improved TG concentration after exercise training. These results suggest that the reduction in circulating RBP4 concentrations may be more associated with exercise-induced improvements in circulating TG concentrations in obese men. Further investigations are needed to confirm the associations between RBP4 and CVD risk factors in response to exercise training in different populations.

\section{Acknowledgements}

This work was supported in part by a Grant-in-Aid for Young Scientists Start-up (19800047) awarded by the Japan Society for the Promotion of Science of Japan.

\section{Disclosure Statement}

The authors declare that there is no conflict of interest.

\section{References}

1 Flegal KM, Carroll MD, Ogden CL, Curtin LR: Prevalence and trends in obesity among US adults, 1999-2008. JAMA 2010;303:235-241.

2 Berghöfer A, Pischon T, Reinhold T, Apovian CM, Sharma AM, Willich SN: Obesity prevalence from a European perspective: a systematic review. BMC Public Health 2008;8:200..

3 Malnick SD, Knobler H: The medical complications of obesity. QJM 2006;99:565-579.

- 4 Maury E, Brichard SM: Adipokine dysregulation, adipose tissue inflammation and metabolic syndrome. Mol Cell Endocrinol 2010;314:1-16. 
- 5 Quadro L, Blaner WS, Salchow DJ, Vogel S, Piantedosi R, Gouras P, Freeman S, Cosma MP, Colantuoni V, Gottesman ME: Impaired retinal function and vitamin A availability in mice lacking retinol-binding protein. EMBO J 1999;18:4633-4644.

- 6 Yang Q, Graham TE, Mody N, Preitner F, Peroni OD, Zabolotny JM, Kotani K, Quadro L, Kahn BB: Serum retinol binding protein 4 contributes to insulin resistance in obesity and type 2 diabetes. Nature 2005;436: 356-362.

7 Cho YM, Youn BS, Lee H, Lee N, Min SS, Kwak SH, Lee HK, Park KS: Plasma retinol-binding protein-4 concentrations are elevated in human subjects with impaired glucose tolerance and type 2 diabetes. Diabetes Care 2006;29:2457-2461.

8 Graham TE, Yang Q, Blüher M, Hammarstedt A, Ciaraldi TP, Henry RR, Wason CJ, Oberbach A, Jansson PA, Smith U, Kahn BB: Retinol-binding protein 4 and insulin resistance in lean, obese, and diabetic subjects. N Engl J Med 2006;354:2552-2563.

- 9 Erikstrup C, Mortensen OH, Pedersen BK: Retinol-binding protein 4 and insulin resistance. N Engl J Med 2006;355:1393-1394.

10 Takashima N, Tomoike H, Iwai N: Retinol-binding protein 4 and insulin resistance. N Engl J Med 2006;355: 1392-1393.

-11 Haider DG, Schindler K, Prager G, Bohdjalian A, Luger A, Wolzt M, Ludvik B: Serum retinol-binding protein 4 is reduced after weight loss in morbidly obese subjects. J Clin Endocrinol Metab 2007;92:1168-1171.

12 Ng TW, Watts GF, Barrett PH, Rye KA, Chan DC: Effect of weight loss on LDL and HDL kinetics in the metabolic syndrome: associations with changes in plasma retinol-binding protein-4 and adiponectin levels. Diabetes Care 2007;30:2945-2950.

13 von Eynatten M, Lepper PM, Liu D, Lang K, Baumann M, Nawroth PP, Bierhaus A, Dugi KA, Heemann U, Allolio B, Humpert PM: Retinol-binding protein 4 is associated with components of the metabolic syndrome, but not with insulin resistance, in men with type 2 diabetes or coronary artery disease. Diabetologia 2007; 50:1930-1937.

14 Broch M, Gómez JM, Auguet MT, Vilarrasa N, Pastor R, Elio I, Olona M, García-España A, Richart C: Association of retinol-binding protein-4 (RBP4) with lipid parameters in obese women. Obes Surg 2010;20:12581264.

15 American Diabetes Association: Diagnosis and classification of diabetes mellitus. Diabetes Care 2008; 31(suppl 1):S55-S60.

16 The Examination Committee of Criteria for 'Obesity Disease' in Japan, Japan Society for the Study of Obesity: New Criteria for 'Obesity Disease' in Japan. Circ J 2002;66:987-992.

17 Nakata Y, Tanaka K, Mizuki T, Yoshida T: Body composition measurements by dual-energy X-ray absorptiometry differ between two analysis modes. J Clin Densitom 2004;7:443-447.

-18 Tanaka K, Takeshima N, Kato T, Niihata S, Ueda K: Critical determinants of endurance performance in middle-aged and elderly endurance runners with heterogeneous training habits. Eur J Appl Physiol Occup Physiol 1990;59:443-449.

19 Friedewald WT, Levy RI, Fredrickson DS: Estimation of the concentration of low-density lipoprotein cholesterol in plasma, without use of the preparative ultracentrifuge. Clin Chem 1972;18:499-502.

-20 Katz A, Nambi SS, Mather K, Baron AD, Follmann DA, Sullivan G, Quon MJ: Quantitative insulin sensitivity check index: a simple, accurate method for assessing insulin sensitivity in humans. J Clin Endocrinol Metab 2000;85:2402-2410.

-21 Vitkova M, Klimcakova E, Kovacikova M, Valle C, Moro C, Polak J, Hanacek J, Capel F, Viguerie N, Richterova B, Bajzova M, Hejnova J, Stich V, Langin D: Plasma levels and adipose tissue messenger ribonucleic acid expression of retinol-binding protein 4 are reduced during calorie restriction in obese subjects but are not related to diet-induced changes in insulin sensitivity. J Clin Endocrinol Metab 2007;92:2330-2335.

22 Gómez-Ambrosi J, Rodríguez A, Catalán V, Ramírez B, Silva C, Rotellar F, Gil MJ, Salvador J, Frühbeck G: Serum retinol-binding protein 4 is not increased in obesity or obesity-associated type 2 diabetes mellitus, but is reduced after relevant reductions in body fat following gastric bypass. Clin Endocrinol 2008;69: 208-215.

23 Choi KM, Kim TN, Yoo HJ, Lee KW, Cho GJ, Hwang TG, Baik SH, Choi DS, Kim SM: Effect of exercise training on A-FABP, lipocalin-2 and RBP4 levels in obese women. Clin Endocrinol 2009;70:569-574.

$\checkmark 24$ Janke J, Engeli S, Boschmann M, Adams F, Böhnke J, Luft FC, Sharma AM, Jordan J: Retinol-binding protein 4 in human obesity. Diabetes 2006;55:2805-2810.

25 Craig RL, Chu WS, Elbein SC: Retinol binding protein 4 as a candidate gene for type 2 diabetes and prediabetic intermediate traits. Mol Genet Metab 2007;90:338-344.

26 Kovacs P, Geyer M, Berndt J, Klöting N, Graham TE, Böttcher Y, Enigk B, Tönjes A, Schleinitz D, Schön MR, Kahn BB, Blüher M, Stumvoll M: Effects of genetic variation in the human retinol binding protein-4 gene (RBP4) on insulin resistance and fat depot-specific mRNA expression. Diabetes 2007;56:3095-3100.

27 van Hoek M, Dehghan A, Zillikens MC, Hofman A, Witteman JC, Sijbrands EJ: An RBP4 promoter polymorphism increases risk of type 2 diabetes. Diabetologia 2008;51:1423-1428.

28 Hirshman MF, Goodyear LJ, Horton ED, Wardzala LJ, Horton ES: Exercise training increases GLUT-4 protein in rat adipose cells. Am J Physiol 1993;264:E882-889. 
29 Stallknecht B, Andersen PH, Vinten J, Bendtsen LL, Sibbersen J, Pedersen O, Galbo H: Effect of physical training on glucose transporter protein and mRNA levels in rat adipocytes. Am J Physiol 1993;265:E128134.

30 Gerber LE, Erdman JW Jr: Retinoic acid and hypertriglyceridemia. Ann N Y Acad Sci 1981;359:391-392.

-31 Cnop M, Havel PJ, Utzschneider KM, Carr DB, Sinha MK, Boyko EJ, Retzlaff BM, Knopp RH, Brunzell JD, Kahn SE: Relationship of adiponectin to body fat distribution, insulin sensitivity and plasma lipoproteins: evidence for independent roles of age and sex. Diabetologia 2003;46:459-469.

-32 Higashiura K, Ura N, Ohata J, Togashi N, Takagi S, Saitoh S, Murakami H, Takagawa Y, Shimamoto K: Correlations of adiponectin level with insulin resistance and atherosclerosis in Japanese male populations. Clin Endocrinol 2004;61:753-759.

-33 Martin LJ, Woo JG, Daniels SR, Goodman E, Dolan LM: The relationships of adiponectin with insulin and lipids are strengthened with increasing adiposity. J Clin Endocrinol Metab 2005;90:4255-4259.

34 Vergès B, Petit JM, Duvillard L, Dautin G, Florentin E, Galland F, Gambert P: Adiponectin is an important determinant of apoA-I catabolism. Arterioscler Thromb Vasc Biol 2006;26:1364-1369.

35 Baratta R, Amato S, Degano C, Farina MG, Patanè G, Vigneri R, Frittitta L. Adiponectin relationship with lipid metabolism is independent of body fat mass: evidence from both cross-sectional and intervention studies. J Clin Endocrinol Metab 2004;89:2665-2671.

-36 Matsuura F, Oku H, Koseki M, Sandoval JC, Yuasa-Kawase M, Tsubakio-Yamamoto K, Masuda D, Maeda N, Tsujii K, Ishigami M, Nishida M, Hirano K, Kihara S, Hori M, Shimomura I, Yamashita S: Adiponectin accelerates reverse cholesterol transport by increasing high density lipoprotein assembly in the liver. Biochem Biophys Res Commun 2007;358:1091-1095.

-37 Pérusse L, Collier G, Gagnon J, Leon AS, Rao DC, Skinner JS, Wilmore JH, Nadeau A, Zimmet PZ, Bouchard C: Acute and chronic effects of exercise on leptin levels in humans. J Appl Physiol 1997;83:5-10.

-38 Kraemer RR, Kraemer GR, Acevedo EO, Hebert EP, Temple E, Bates M, Etie A, Haltom R, Quinn S, Castracane VD: Effects of aerobic exercise on serum leptin levels in obese women. Eur J Appl Physiol Occup Physiol 1999;80:154-158.

-39 Thong FS, Hudson R, Ross R, Janssen I, Graham TE: Plasma leptin in moderately obese men: independent effects of weight loss and aerobic exercise. Am J Physiol Endocrinol Metab 2000;279:E307-313.

-40 Dekker MJ, LeeS, Hudson R, Kilpatrick K, Graham TE, Ross R, Robinson LE: An exercise intervention without weight loss decreases circulating interleukin- 6 in lean and obese men with and without type 2 diabetes mellitus. Metabolism 2007;56:332-338.

41 Lim S, Choi SH, Jeong IK, Kim JH, Moon MK, Park KS, Lee HK, Kim YB, Jang HC: Insulin-sensitizing effects of exercise on adiponectin and retinol-binding protein-4 concentrations in young and middle-aged women. J Clin Endocrinol Metab 2008;93:2263-2268. 